Revista do SELL

v. $4, n^{\circ} .2$

ISSN: $1983-3873$

\title{
DE MINAS PARA O RIO: DRUMMOND E ALGUMAS CENAS CARIOCAS
}

FROM MINAS TO RIO: DRUMMOND AND SOME RIO'S SCENES

\author{
Regina Célia dos Santos Alves \\ Universidade Estadual de Londrina \\ Laysa Louise Silva Beretta \\ Universidade Estadual de Londrina
}

\begin{abstract}
RESUMO: Carlos Drummond de Andrade tornou-se conhecido, sobretudo, por sua produção poética, sendo considerado um dos maiores poetas brasileiros. Todavia, o autor foi também um grande prosador, exercitando-se em gêneros diversos, como o conto, a crônica, a notícia e outros. Inúmeros temas percorrem a sua produção literária, como, por exemplo, a cidade e a vida urbana, que aqui nos interessa mais de perto. Tendo isso em vista, o objetivo do presente trabalho é a análise de três crônicas de Drummond, "Solilóquio", de Notícias e não notícia faz-se a crônica (1974) "A cidade sem meninos" e "A descoberta do mar", ambas de Cadeira de balanço (1966), nas quais o Rio de Janeiro é tema central.
\end{abstract}

PALAVRAS-CHAVE: Carlos Drummond de Andrade; Rio de Janeiro; crônica.

ABSTRACT: Carlos Drummond de Andrade is known mainly for his poetry and he is considered one of the greatest Brasilian poet. However, the author was also a great prose writer and, beside poems, he wrote short stories, chronicles, news and more. His literature runs through several themes, such as the city and urban life, for example, that here is concerned. So, this paper aims to analyse three chronicles written by Carlos Drummond de Andrade, "Solilóquio", from De Notícias e não notícias faz-se a crônica (1974), "A cidade sem meninos" and "A descoberta do mar", from Cadeira de balanço (1966), in which the Rio de Janeiro city is the main theme.

KEYWORDS: Carlos Drummond de Andrade; Rio de Janeiro; Chronicle.

\begin{abstract}
"A cidade não cria, mas consome. Já que é o empório para onde afluem os bens arrancados dos campos e das minas, para ela acorrem os espíritos mais vivos da província e as ideias dos grandes solitários. A cidade é como uma fogueira que ilumina porque queima o que foi criado longe dela e por vezes contra ela. Todas as cidades são estéreis. Nelas nasce proporcionalmente pouca gente e quase nunca alguém de gênio. Nas cidades goza-se, mas não se cria; ama-se, mas não se gera; consome-se, mas não se produz". Giovanni Papini
\end{abstract}

Carlos Drummond de Andrade (1902-1987) nasceu em Itabira do Mato Dentro, Minas Gerais. Começou a carreira de escritor como colaborador do Diário de Minas, que aglutinava os adeptos locais do incipiente movimento modernista mineiro. Formou-se em 


\section{Revista do SELL}

v. $4, n^{\circ} .2$

ISSN: $1983-3873$

Farmácia na cidade de Ouro Preto, em 1925. Ainda em Minas Gerais, fundou, com outros escritores, A Revista, que, apesar de vida curta, foi importante veículo de afirmação do Modernismo no estado.

Em 1934, transferiu-se para o Rio de Janeiro, onde foi chefe de gabinete do ministro da Educação, Gustavo Capanema e, depois de algum tempo, funcionário do Patrimônio Histórico e Artístico Nacional.

A atividade literária de Carlos Drummond de Andrade nunca cessou, mesmo com o cargo público em exercício. Escreveu poesias, contos e crônicas, mas foi o primeiro desses gêneros que o eternizou no contexto histórico nacional e internacional. Drummond é o poeta modernista lembrado, principalmente, por obras como Sentimento do Mundo (1940), José (1942) e A Rosa do Povo (1945).

A colaboração com a imprensa começou em 1945, quando deixou a chefia do gabinete de Capanema e passou a trabalhar como um dos editores do Imprensa Popular, diário lançado pelo Partido Comunista Brasileiro. Alguns meses mais tarde, o poeta se afastou do jornal por discordar de alguns ideais políticos disseminados pelo veículo.

No decorrer dos anos colaborou com diversos jornais, mas é em 1954 que o autor passa a escrever e publicar crônicas. De 1954 a 1969 escreve para o Correio da Manhã e de 1969 a 1984 para o Jornal do Brasil.

Em 1957, o cronista passou a organizar e publicar as suas crônicas em livros. Em 1957, Fala, Amendoeira; em 1962, A Bolsa \& a Vida; em 1966, Cadeira de Balanço; também de 1966, João Brandão; em 1970, O Poder Ultrajovem; em 1972, De Notícias \& Não Notícias Faz-se a Crônica; em 1974, Os Dias Lindos em 1977; Boca de Luar em 1984; Moça Deitada na Grama em 1987; Auto-Retrato e Outras Crônicas em 1989; Vó Caiu na Piscina, em 1996 e Quando É Dia de Futebol em 2002. Moça Deitada na Grama, Auto-retrato e Outras Crônicas, Vó Caiu na Piscina e Quando é Dia de Futebol foram publicações póstumas.

Apenas o grande sucesso como poeta poderia ofuscar a representatividade da extensa e excelente produção do Drummond cronista, mas não o fez. O desempenho e o reconhecimento do autor neste gênero são confirmados com os dados expostos por Luís Carlos Santos Simon:

Cadeira de balanço está na $19^{\circ}$ edição; O poder ultrajovem encontra-se na $17^{\circ}$ edição; Fala, Amendoeira já atingiu a $14^{\circ}$ edição; $A$ bolsa e a vida está na $13^{\circ}$; e Boca de luar, lançado em 1984, já teve II edições. Se quisermos comparar com o desempenho dos livros de poemas, não teremos 


\section{Revista do SELL}

v. $4, n^{\circ} .2$

ISSN: $1983-3873$

diferenças tão significativas: $A$ rosa do povo, possivelmente a publicação mais conhecida, está na $24^{\circ}$ edição (SIMON, 2011, p. 30).

É possível perceber que o "segundo ofício" de Drummond está, também, presente na estante dos seus leitores. O trabalho aparentemente mais descompromissado e despretensioso também deve encantar ao leitor, talvez porque o autor, na prosa, explore os grandes temas que percorrem a sua poesia, pois, assim como afirma Lélia Coelho Frota no prefácio de Os dias lindos, "vate e cronista são afinal uma só cabeça que pensa e um único coração que sente" (FROTA, 2003, p.10).

A liminaridade entre os dois gêneros é indiscutível na crônica de Drummond. O autor, inclusive, escreveu inúmeras crônicas em verso, de cujo conjunto resultou o Versiprosa. A fronteira tênue entre os dois gêneros explica, também, o título de "cronistapoeta" que recebe de Beatriz Resende em Cronistas do Rio. Embora o objetivo nesse trabalho não seja propriamente discussões em torno do gênero crônica, é importante registrar que o gênero, marcado pela leveza, pelos acontecimentos banais e não raro sem grandiosidade do dia-a-dia, encontra na cidade um ambiente bastante fértil, laço que se estreita ainda mais quando se trata do Rio de Janeiro. Não por acaso, um itabirano como Drummond, afirma que "O Rio ainda é o maior e melhor assunto, além de ser o melhor ponto de vista, o melhor terraço para se divisar qualquer assunto" (1984, p.120). As crônicas nos mostram que o poeta, como cronista, torna-se extremamente carioca.

Ainda que Rubem Braga, a propósito de Fala, amendoeira, afirme a timidez de Drummond em explorar a cidade do Rio, ficando esta, no dizer do grande cronista, restrita a um espaço diminuto, nos limites do "que atinge sua casa, seu quintal, sua calçada, no máximo seu canto de praia" (BRAGA, p. 40), o Rio de Janeiro, como já dito, é personagem de grande destaque na prosa do autor, com seus prazeres, mazelas e belezas. Em Fala, amendoeira, está a Rua São José e seus sebos, a Livraria José Olympio, crônicas em modelos de cartas endereçadas ao prefeito do Distrito Federal e, desde aquele momento, João Brandão, outra grande personagem das crônicas de Drummond.

Alguns traços da poesia do autor, reiteradamente mencionados pela crítica, parecem também compor o fundamento de sua escrita em prosa, como a luta corporal com a palavra no processo de criação, a obstinada busca de compreensão da "máquina do mundo" e o incansável desejo de comunhão, como mostra Afrânio Coutinho: 


\section{Revista do SELL}

v. $4, n^{\circ} .2$

ISSN: $1983-3873$

Sua essencialidade lírica e emocional [de Drummond], exprimindo-se através de uma profunda consciência artística e artesanal, conduziu-o a uma cristalização e humanização, terna e suave na compreensão da "máquina do mundo", da angústia de seu tempo e do desarvorado do homem moderno. Tornou-se, assim, um artista completo, de amplo sentido coletivo, falando por todos os que sofrem, mas também dando-lhes a sua palavra fraterna, o alimento de sua poesia, a fim de levá-los a beber a beleza das coisas - o outro lado da vida - as coisas simples, as árvores, os pássaros, o amor (COUTINHO, p.10).

Os comentários de caráter sintético de Afrânio Coutinho parecem providenciais quanto à prosa do escritor itabirano e definem com precisão as crônicas que aqui serão abordadas, onde a dor do desarranjo do mundo não impede o apelo para as coisas simples da vida e para a comunhão, nem mesmo quando se tem à frente o tumulto e o desajuste da vida urbana.

Dois livros muito nos interessaram no que tange à obra de Drummond: Cadeira de Balanço (1966) e De Notícias \& Não Notícias Faz-se a Crônica (1974), nos quais, na contramão do que afirma Braga acerca de Fala, amendoeira, o escritor expande e amplia sua leitura sobre a cidade, indo tocar, com grande força lírica e também crítica, nos mais profundos dramas da cidade moderna, cuja dinâmica cotidiana engendra situações de intenso desconforto, desconfiança, medo e descrença para o homem urbano.

Para o presente trabalho, importa-nos observar certos aspectos da cidade e da vida urbana a partir da abordagem de três crônicas de Drummond: "A descoberta do mar" e "A cidade sem meninos", de Cadeira de balanço e "Solilóquio", de Notícias \& não notícias faz-se a crônica. Nos três textos, embora a capital carioca seja expressa como local de desarranjo do mundo, a constatação da aridez da vida urbana não impede o cronista de buscar nas pequenas - e talvez por isso mesmo grandes - maravilhas da vida o caminho da comunhão com o outro e com a vida, até mesmo onde ela parece nem mesmo mais existir.

Em "A descoberta do mar", última crônica da seção "Cariocas", de Cadeira de balanço, a observação de um acontecimento banal, a parada de um ônibus escolar na praia de Copacabana, filtrada pelo olhar sensível do cronista, dá origem a um texto belo e profundo, que põe em cena um dos traços mais inquietantes da cidade, ou seja, a desigualdade, a fazer com que seus habitantes vivam apartados, como se não pertencessem a um mesmo local.

$\mathrm{Na}$ crônica, essa cidade partida pode ser observada, sobretudo, em alguns pares dicotômicos, como zona Sul $x$ subúrbio, conhecimento $x$ desconhecimento e riqueza $x$ 


\section{Revista do SELL}

v. $4, n^{\circ} .2$

ISSN: $1983-3873$

pobreza. Ao observar o ônibus escolar com os meninos, logo na primeira cena a divisão dos espaços já se torna evidente: "Os alunos daquela escola de subúrbio nunca tinham visto o mar. Saíram em excursão, de ônibus, pediram ao motorista que desse uma volta pela Zona Sul. Viram, ficaram deslumbrados" (DRUMMOND, p.990).

Subúrbio e Zona Sul são postos em confronto nesse início de texto e apontam para uma dura realidade da cidade: a distância em que vivem seus habitantes. Embora não seja uma percepção nova acerca desse distanciamento existente no Rio, pois a cidade partida já se vinha construindo de longa data, em especial a partir do projeto reformista civilizatório do prefeito Pereira Passos nos primeiros anos do século $\mathrm{XX}$, a dividir de forma mais incisiva a cidade, quando retira a população mais pobre das áreas centrais do Rio, obrigando-na a buscar locais mais distantes (e mais baratos) onde pudesse se assentar, Drummond trata com singularidade e forte apelo lírico esse incômodo que é a desigualdade urbana. Assim, faz com que, por meio do humano - dos meninos - distantes na cartografia física e social da cidade, o contato entre o subúrbio e a Zona Sul possa ocorrer:

Não me contaram onde é a escola; sente-se que fica longe, sem esperança, num desses inúmeros cafundós do Rio que não são o Rio, e que a gente mal percebe de avião, ponto cinzento ou pardo na pele da cidade. Ou quem sabe se a trinta minutos da praia, porque não é a distância nem a má conserva das estradas que não permite a uma parte da população tomar conhecimento de nossas amenidades: é a pobreza. $O$ custo da condução e do farnel impede à família de seis pessoas, residente no Rio, realizar a aventura deliciosa de passar o domingo no Rio, simplesmente saindo de casa pela manhã e regressando à noitinha (DRUMMOND, p.990).

Se a cena inicial trazida pela crônica aponta para a diferença e distanciamento dos espaços, subúrbio e Zona Sul, nesse outro momento, à separação espacial soma-se a separação social e econômica. No sentir do cronista, mais que a distância física, a distância social deve ser considerada, pois a pobreza, a marcar os subúrbios, mantém seus habitantes à margem, na ignorância da própria cidade.

$\mathrm{Na}$ observação dessa adversidade urbana, Drummond desenha a cidade enquanto um organismo, enquanto um ser (tem pele) e o subúrbio como uma pinta ou mancha escura ("ponto cinzento ou pardo") a insistir com sua presença insignificante, quando muito intrusa e indesejável. Todavia, esse "ponto cinzento ou pardo" - expressão reveladora, pois, enquanto qualidade do subúrbio parece remeter ao grupo que aí vive, 


\section{Revista do SELL}

v. $4, n^{\circ} .2$

ISSN: $1983-3873$

em sua maioria negros e mulatos, historicamente mais pobres e à margem da sociedade - é sinônimo de vida na imagem dos meninos, abandonados e ignorantes (estão distantes do centro e sequer conhecem o mar, o bem maior da cidade), mas sedentos de descobertas, de vivência desse corpo maior a que pertencem tão insignificantemente que nem pode se ver do alto, mas que, no entanto, são dele parte.

Do olhar sensível e atento do escritor brota o desejo de comunhão, de abertura da cidade para todos, independente do lugar e da importância que nela possam ter, pois a expressão última deveria ser a do humano e não a do dinheiro:

Quando se fala em turismo na Guanabara, dá vontade de propor um turismo paroquial, dominical, para meninos e meninas que crescem ignorantes da cidade, sonhando com o mar impossível. Não ganharíamos um dólar com isso, mas eles voltariam menos pobres a seus subúrbios áridos, e o Rio se tornaria um pouco mais humano, com a população vinculada ao bem comum da paisagem. Que custa nos tornarmos condôminos do azul e da onda? (DRUMMOND, p.990).

Diversamente da conduta da cidade, que separa e segrega, a postura e proposição do cronista, que passa a falar na primeira pessoa do plural e no futuro do pretérito, a indicar uma ação conjunta e possível no futuro, encenam a união e a comunhão, na atitude simples e despretensiosa de um turismo paroquial e dominical para crianças que desconhecem a própria cidade, vivendo em lugares recônditos da mesma, condenadas a permanecer do outro lado, numa espécie de degredo, privada de coisas banais e prazerosas que a cidade thes poderia oferecer, como mergulhar o olhar na imensidão verde-arroxeada do mar e sentir o toque da areia nos pés.

O Rio mais humano, assim, seria aquele desprovido de barreiras e distâncias, a colocar a vida e o homem acima de qualquer interesse financeiro: "não ganharíamos um dólar com isso" (p.990). Desejo ideal de comunhão da cidade com seu habitante, do homem com o homem, do homem com a natureza, presente na força da expressão "condôminos do azul e da onda", em que a palavra condôminos aponta para o domínio mútuo do bem natural, a ser desfrutado por todos, sem diferença ou imposição de soberania, contrariamente à cidade partida e segregadora.

A experiência do menino com o mar, assim, aos olhos sensíveis, líricos e sedentos de comunhão do cronista, apresenta-se como um momento ímpar na descoberta de uma sensação e mesmo de um mundo totalmente novo e fascinante, 


\section{Revista do SELL \\ v. $4, n^{\circ} .2$}

ISSN: $1983-3873$

imerso na imensidão do mar e na variedade de sensações (visão, toque, cheiro) ainda não experimentadas:

O menino apenas esticou o pé na areia úmida, sentiu o arrepio do contato, menos que isso; a espuma tocou no bico do sapato, espalhou-se de leve, o menino empalideceu, coração batendo de conhecer o mar, súbita iluminação entre sua biboca triste e o marulho tocável (DRUMMOND, p.990).

Ao que parece, a descoberta do mar, título da crônica, implica de fato três outras importantes descobertas que surgem a partir da experiência com o mar: a da liberdade, o poder sentir das mais diversas formas o mar e sua imensidão insondável; a da cidade, a de sua outra face, a da paisagem natural, atrativa e estimulante, a envolver o visitante deslumbrado com a novidade, cheia de fascínio e sensações novas; e a do mundo, a de uma realidade até então desconhecida, capaz de transformar aqueles meninos do subúrbio, perdidos, ignorados e ignorantes em seus cafundós e bibocas tristes, em "homenzinhos nostálgicos e importantes, que podem dizer aos companheiros. "O mar? É aquela coisa infinita, azul, verde-arroxeada, que solta um gemido fundo e deixa uma neblina salgada na cara da gente..."”' (DRUMMOND, p.991).

$\mathrm{Na}$ definição profundamente poética, o mar, ainda que ligeiramente "tocado" leva a um estado singular e de comunhão dos meninos - agora crescidos em sabedoria e experiência, por isso homenzinhos - com a natureza, agora parte de seu ser, pois sentem-na no corpo e na alma, sensorial e emocionalmente.

Na crônica "A cidade sem meninos", também da seção "Cariocas", de Cadeira de balanço, instaura-se uma atmosfera de fim dos tempos, ou melhor, de fim da própria cidade, a eliminar a vida infantil de seu centro. O desejo de comunhão ainda permanece, mas bastante comprometido em vista da certeza de ser algo cada vez menos provável diante da aridez e sordidez urbanas.

Nessa crônica, o destaque é o centro do Rio, local de onde partirá a constatação da falência da cidade, que o censo realizado pelas professoras ajuda a confirmar quando evidenciam a ausência de crianças nesse local: "As professoras que fazem o censo escolar do Rio apuraram um vazio de que já desconfiávamos: não há mais crianças no centro da cidade" (DRUMMOND, p.981).

Assim como em "A descoberta do mar", porém de uma perspectiva muito mais desolada, o cronista continua a expor o desacerto do mundo, da vida nas grandes cidades, atropeladas por um crescimento, no mínimo, insólito. Nesse espaço, destaca-se 


\section{Revista do SELL}

v. $4, n^{\circ} .2$

ISSN: $1983-3873$

uma falta, um vazio fundamental, há muito já percebido pelo eu, cujo "olhar investigativo como o de um cientista que busca conferir suas suspeitas" (MARIA, p.14), confirma a sua desconfiança, a da ausência de crianças no centro e, mais ainda, traz à cena a amargo significado de criança na cidade que a aboliu de seu centro. Aí, significa ornamento, espécime raro, antiguidade, excedente incômodo.

O aparente humor do relato não elimina, todavia, o tom desencantado e desolado em relação ao futuro:

Não tinham meninos. Algum raro espécime que se vê na rua vem do Norte ou do Sul da cidade, para fazer companhia à mãe, sofre no dentista, comprar sapato em liquidação. Há ruas onde faz muitos anos não passa um garoto. E janelas onde eles nunca se debruçaram para espiar as árvores ou a lua, porque também essas antiguidades desapareceram do centro (DRUMMOND, p.981).

O desaparecimento da criança não está isolado nessa realidade, mas corresponde ao desaparecimento de certas ações (debruçar-se na janela) e de certos elementos naturais (as árvores e a lua) que já não fazem mais parte da paisagem do centro, transformando-se em coisas do passado, sem importância, a não ser para o cronista, sedento de vida humana e de comunhão, fortemente representadas pelas crianças, agora ausentes.

A cidade sem meninos, dessa forma, aponta para um mundo caótico ao projetar um futuro estéril em que os adultos desconhecem o que vem a ser uma criança:

Num sobrado da Rua Camerino, o ocupante de uma fração de quarto no segundo andar, à pergunta sobre crianças, respondeu:

- Que é isso?

Perdera a noção. A traços largos, a moça explicou-lhe o que é uma criança. Ele ouviu e admitiu que devem ser interessantes, mas não havia espaço em seu domicílio para esse ornamento (DRUMMOND, p.981).

Isolados em seus mundos e em seus espaços cada vez mais diminutos ("uma fração de quarto"), os adultos mostram-se ignorantes em relação à vida infantil e ao vigor que ela assinala. A ausência dessa vida no centro condena o local à monotonia diurna das obrigações tediosas do trabalho, ao estado de "morte" noturna, uma vez que se limita às construções quando todos dali saem para o tão esperado descanso do lar, onde há vida, conversa, risada, choro de criança, dor de barriga, barulho, pigarro, descarga (DRUMMOND, p.981). No centro, “a vida acaba às 19 horas". Homens e mulheres fogem 


\section{Revista do SELL}

v. $4, n^{\circ} .2$

ISSN: $1983-3873$

literalmente para bairros distantes, como se houvesse estourado a revolução ou a peste nos locais de trabalho (DRUMMOND, P.981).

Sem vida adulta e, mais ainda, sem meninos, o centro parece condenar a sua própria existência e, por extensão, a da própria cidade. Enquanto centro, enquanto coração do núcleo urbano, dele deveria originar o pulsar da vida a espraiar-se por todo o organismo da cidade. No entanto, a crônica de Drummond mostra, ao trazer à cena a recenseadora, que constata por meio da pesquisa a ausência de crianças no centro, espécie de animal extinto que alguns sequer chegaram a conhecer, o estado grave de saúde desse organismo urbano, falido em seu núcleo vital ao ceder incondicionalmente à lógica do progresso, à fúria urbanística e capitalista, a esterilizar a cidade:

"Aqui outrora brincaram meninos..." A cidade multiplica-se, a casa sede lugar ao edifício, o edifício vira constelação de escritores, o menino fica sendo excedente incômodo... Onde está o menino, para onde foi o menino? É assim que morrem as cidades (DRUMMOND, p. 982).

A frase, "Aqui outrora brincaram meninos", que pode tanto remeter a uma inscrição colocada no centro da cidade para lembrar o tempo de outrora em que esses seres existiram, quanto à mulher que diz à recenseadora que conhece criança por que teve vários filhos, ou ao poeta que aproxima seus versos da própria vida infantil, aponta para o ontem vivo - repleto de meninos -, mas de todo modo menos lucrativo (a criança, improdutiva, passa a ser "excedente incômodo") cede lugar ao hoje (sem vida infantil e casas), mas rentável, o que se estampa na paisagem da cidade por meio das construções arquitetônicas a dominar o centro, os edifícios com suas "constelações de escritórios".

Ao perscrutar esse lado triste e desolado da vida urbana, a crônica de Drummond apela mais uma vez, como em "A descoberta do mar", para a necessidade de comunhão, para a experimentação do contato com o outro, com a criança, sinônimo de vida, simplicidade e desprendimento, atributos praticamente apagados no âmago da cidade, tomado pela lógica e dinâmica do dinheiro.

Das três crônicas aqui abordadas, o olhar mais angustiado sobre a cidade e sobre a "máquina do mundo" parece intensificar-se em "Solilóquio", De notícias \& não notícias faz-se a crônica. Nessa obra, sobretudo na seção "Cidades", o cronista apresenta o cotidiano da vida de uma cidade que sofre alterações diárias no seu espaço físico. Nas seis crônicas da referida seção, o gauche e tímido que a tudo assiste aponta para as aporias do rápido e destruidor processo de urbanização. 


\section{Revista do SELL}

v. $4, n^{\circ} .2$

ISSN: $1983-3873$

"Solilóquio" é construída como uma grande interrogação, do primeiro ao último período. Os questionamentos e as indagações perturbadoras apontam para o estado de incerteza do eu quanto ao futuro da cidade e do homem que nele vive (inclusive ele mesmo) e para a certeza de mudanças drásticas já vivenciadas no âmbito da cidade, a indicar um futuro caótico e absurdo, de total destruição dos locais e dos movimentos de reconhecimento e pertencimento do sujeito a constranger os traços de legibilidade da cidade. Esta se transforma em outra, que em sentido algum se mostra familiar:

Vão tirar o terminal do meu ônibus do centro da cidade, vão tirar do centro da cidade o meu ônibus, vão me tirar do centro da cidade? Vão tirar da cidade o centro da cidade, vão tirar da cidade toda a cidade, vão fazer o que da cidade? Vão plantar uma cidade nova no lugar da cidade carcomida, vão desistir de manter as ruínas da cidade, vão decretar que cidade não é mais de a gente viver? Vão fazer ruas de cima para baixo, em forma de cisterna, para o que já se abrem os competentes buracos e se desaconselha andar na superfície para não prejudicar as obras? (DRUMMOND, 1972, pp. 41-2).

O Rio apresentado na crônica define-se como um local caótico, em que o indivíduo é deslocado de seu lugar, perdendo suas referências (o terminal de ônibus), a realidade conhecida aparece subvertida de forma insólita, sendo que o homem tem que se acostumar às ruas subterrâneas, a desviar das intermináveis obras, a saltar por sobre os veículos para poder caminhar e a obedecer a regras cada vez mais duras e opressoras.

No desenho dessa paisagem absurda, é interessante observa o uso exaustivo que Drummond faz do verbo ir, conjugado na terceira pessoa do plural, de modo a não determinar a quem o sujeito "eles" se refere. Essa estratégia de construção parece ser intencional e ter um sentido ambivalente. Por um lado, numa atitude irônica, os sujeitos da ação, o "eles", embora não nomeados, podem fazer referência às autoridades da época empenhadas em uma nova remodelação do Rio de Janeiro, o que ocorre entre os anos de 1960 e 1975, logo após perder a posição de capital federal e tornar-se cidade-estado da Guanabara. A reforma urbanística visava a um revigoramento político, econômico e social da cidade, bastante abalada, dentre outros aspectos, pela transferência da capital para Brasília.

É nesse momento também que se instaura a ditadura militar e o termo "eles", implícito no verbo, pode também se referir à elite governante, a ditar com mãos de ferro as regras de transformação do ambiente urbano e de conduta humana, sem qualquer explicação plausível, daí as duras normas gratuitas: "Vão dizer quantos pessoas podem 


\section{Revista do SELL \\ v. $4, n^{\circ} .2$ \\ ISSN: $1983-3873$}

sair de casa, a quantas horas, por quanto tempo, e por onde será permitido caminhar, durante quantos minutos..." (ANDRADE, 1972, p.42).

Por outro lado, a indeterminação dos sujeitos da ação também poderia levar ao sentido de - no mundo desorientado, descentrado e em que o sujeito perde suas referências e seu território, como mostrado pela crônica - incapacidade de determinação dos lugares do poder, dos agentes concretos das mudanças. Todo e qualquer um pode ter sua parcela de responsabilidade (os governantes, os empresários, os operários das obras, a população) sem, no entanto, no emaranhado e na caos da situação apresentada, ser possível definir com precisão o ator e o grau de participação no que quer que seja.

De qualquer maneira, "eles", ainda que não determinados na crônica, expressam uma ação futura, mas certa. São, no texto de Drummond, sinônimo de inimigo, pois que diretamente responsáveis pela desorientação do sujeito, abolindo a paisagem urbana como familiar, como casa, como lar, como centro, não apenas da cidade, mas de si mesmo: o terminal do ônibus, o centro, as ruas.

No pulsar do sentimento de perda provocado pela certa e inabalável mudança/destruição da cidade cara ao eu, a crônica contrapõe a cidade carcomida e em ruínas, mas de todo modo local de pertencimento do eu e aquele que reconhece como abrigo acolhedor, à cidade nova, cuja ordem parece tremendamente insólita, a criar um novo espaço, onde o homem não tem lugar nem vez, onde há ausência total de comunhão, já que as pessoas, espécies de autômatos, são totalmente comandadas por forças proibitivas.

Diante da visão desencantada e descrente quanto aos rumos da "nova cidade", a conclusão apocalíptica: "Vão acabar com a cidade, todas as cidades, vão acabar com o homem e a mulher também, vão fazer o quê, depois que eles mesmos acabarem?" (ANDRADE, 1972, p.42). Ao sujeito angustiado e só no turbilhão da mudança, num mundo surdo a vozes dissonantes, resta apenas um grito solitário, o falar para si mesmo, o solilóquio.

Desse modo, a crônica "Solilóquio" encerra, junto das crônicas analisadas anteriormente, um crescendo no que se refere à conflituosa relação entre o homem e o espaço, no caso a cidade que, da perspectiva apresentada, só pode viver se fizer do humano seu bem maior. 


\section{Revista do SELL}

v. $4, n^{\circ} .2$

ISSN: $1983-3873$

\section{CONSIDERAÇÕES FINAIS}

Nas três crônicas aqui analisadas, "A descoberta do mar", a "Cidade sem meninos" e "Solilóquio", pequeno recorte da produção em prosa de Drummond em que a atenção do autor se debruça sobre a cidade do Rio de Janeiro, a cidade literariamente imaginada e ressignificada pelo autor apresenta-se como um espaço de grande complexidade, cuja dinâmica contraditória permite experimentar as sensações e os sentimentos mais díspares. De qualquer maneira, a capital carioca parece funcionar, como afirma o autor, como "o melhor terraço para se divisar qualquer assunto" (1984, P.120).

$\mathrm{Na}$ leitura feita das três crônicas, questões recorrentes na prosa drummondiana, como a observação atenta do desconcerto do mundo e a busca pela comunhão estão presentes com grande força. Os três textos, quando colocados lado a lado, parecem construir uma espécie de crescendo em relação ao desconforto visto pelo eu em relação à vida moderna e à dificuldade de comunhão, cada vez maior em um espaço cuja lógica pouca ou nenhuma importância concede ao humano.

Desse modo, em "A descoberta do mar", a experiência da comunhão e a esperança ainda parecem possíveis, não obstante a desigualdade e o desagravo da cidade. Nessa crônica, o eu tem uma proposta - o turismo dominical, a ausência de barreiras entre as pessoas - e não se abate diante das idiossincrasias urbanas, encantando-se com a cena dos garotos que descobrem o mar pela primeira vez.

E "Cidades sem meninos", por outro lado, o tom é mais amargo, presente na constatação - não só intuitiva, mas comprovada cientificamente pelo censo -, de que o centro da cidade não possui mais crianças, metaforicamente concebidas na crônica como fonte de vida na cidade. Banindo as crianças do centro, a cidade condena-se à própria morte.

"Solilóquio", por fim, apresenta uma atmosfera mais apocalíptica, desesperada, que a própria ideia de solilóquio reforça, já que o eu encontra-se solitário em sua dor, sem ouvintes, a não ser ele mesmo. De qualquer maneira, o desejo do eu ainda é de pertencimento à cidade, a um espaço que se faz familiar, seja pelo ponto de ônibus no centro ou mesmo pelos traços carcomidos do ambiente degradado.

Em resumo, é possível dizer que, no exercício da crônica, desse texto híbrido que flerta com o jornal e com a literatura, que busca sua matéria "ao rés do chão", como afirma Candido, no fato miúdo e na banalidade do dia-a-dia, Drummond, na leitura do Rio de Janeiro, assim como de outros temas que persegue, como afirma Luzia de Maria, 


\title{
Revista do SELL
}

v. $4, n^{\circ} .2$

ISSN: $1983-3873$

deixa-se revelar pelo:

\begin{abstract}
Olhar observador como de uma criança descobrindo o mundo; olhar investigativo como o de um cientista que busca conferir suspeitas; olhar privilegiado como o dos pintores que trazem luz nos olhos; olhar zeloso como o dos namorados, capaz de aspergir ternura sobre as pequenas fragilidades da natureza humana; olhar de esperto como o dos jogadores de cartas, que colhem num relance detalhes mínimos e fugidios; olhar de mágico, capaz de fundir pequenas porções de vida a outro tanto de imaginação, acrescentar o paciente trabalho com palavras e tirar da manga ou da cartola a história que nos surpreende, a reflexão que nos desperta, a evidência que não enxergávamos, a crônica que depois de lida permanece em nós (MARIA, 1997, p.14).
\end{abstract}

Com efeito, Minas Gerais formou um grande cronista carioca. Ainda que, como dizem, fosse de gestos tímidos e provincianos, Drummond foi, sobretudo, um grande cronista da cidade do Rio de Janeiro, atento ao espaço urbano e sensível diante do desconcerto dos homens nascidos na cidade grande.

Enfim, seja como poeta, ou como cronista, Carlos Drummond de Andrade testemunhou e registrou seu tempo convertido em palavra, e como palavra o ofereceu à posteridade.

\section{REFERÊNCIAS:}

ANDRADE, Carlos Drummond de. Conversa de livraria: 1941 e 1948. Porto Alegre: Editora Age e São Paulo: Editora Giordano, 2000. . De notícias e não notícias faz-se a crônica. Rio de Janeiro: Editora José Olympio, 1979.

Obra completa. 2. ed. Rio de Janeiro: Aguilar, s.d.

ANDRADE, Carlos Drummond de. Cadeira de Balanço. Rio de Janeiro: Editora Record, 2009.

. Primeira vez. In: Quatro Vozes. Rio de Janeiro: Editora Record, 1984.

2009.

BRAGA, Rubem. Introdução geral. In: ANDRADE, Carlos Drummond de. Obra completa. Rio de Janeiro: Aguilar, s.d. 


\section{Revista do SELL \\ v. $4, n^{\circ} .2$ \\ ISSN: $1983-3873$}

COUTINHO, Afrânio. Nota preliminar. In: BRAYNER, Sônia (org.). Carlos Drummond de Andrade. Rio de Janeiro: Civilização Brasileira, 1977.

FROTA, Lélia Coelho. Prefácio. In: ANDRADE, Carlos Drummond de. Os dias lindos. São Paulo: Editora Record, 2003.

MARIA, Luzia de. Da manga ou da cartola a história que nos surpreende. In: ANDRADE, Carlos Drummond de. As palavras que ninguém diz. 2. ed. Rio de Janeiro: Record, 1997. RESENDE, Beatriz (org.) Cronistas do Rio. Rio de Janeiro: José Olympio, 1995.

SANT'ANNA. Affonso Romano de. Drummond: o gauche no tempo. Rio de Janeiro: Editora Record, 1992.

SIMÕES, João Gaspar. Introdução geral. In: ANDRADE, Carlos Drummond de. Obra completa. Rio de Janeiro: Aguilar, s.d.

SIMON, Luís Carlos Santos. Duas ou três páginas despretensiosas. Londrina:EDUEL, 2011. 